\title{
Perhitungan Nilai Maksimum Thrust, Torque, dan Efficiency Propeller Tipe B-4 Series pada Kapal Tugboat dengan Modifikasi Diameter, Rake, dan Pitch menggunakan Metode Komputasi
}

\author{
Kelly Cristin Prananda Lumbanraja ${ }^{1}$, Deddy Chrismianto ${ }^{2}$, Samuel $^{3}$ \\ Universitas Diponegoro, Semarang, Indonesia \\ Email: kcplumbanraja@gmail.com ${ }^{1}$, deddychrismianto@lecturer.undip.ac.id ${ }^{2}$, \\ samuelaritonang@lecturer.undip.ac.id ${ }^{3}$
}

Received 01 Januari $2021 \mid$ Revised 09 Maret $2021 \mid$ Accepted 15 Maret 2021

\begin{abstract}
ABSTRAK
Kapal tugboat digunakan untuk membantu kapal yang akan masuk atau keluar pelabuhan. Untuk mendorong dan menarik kapal maka diperlukan propeller sebagai mesin penggerak kapal. Kinerja propeller pada kapal tugboat sangat vital dalam menunjang fungsi tugboat tersebut. Pada penelitian ini akan melakukan modifikasi pada rake, diameter, dan pitch propeller B-Series pada kapal tugboat dengan metode komputasi sehingga diperoleh nilai efficiency yang paling baik. Simulasi pada penelitian ini akan menggunakan persamaan Reynolds-Averaged Navier Stokes (RANS) dan mendiskripsikan aliran turbulen dengan menggunakan model $k-\varepsilon$ dan $k-\omega$. Hasil nilai torque, thrust, dan efficiency yang sudah disimulasikan akan di verifikasi dengan diagram Wageningen. Wageningen adalah karakteristik propeller B-series yang sudah dipublikasikan dari hasil eksperimen. Dari hasil simulasi CFD diperoleh kesimpulan torque paling minimum terletak pada modifikasi dengan rake $0^{\circ}$, pitch 1,36 , dan diameter 1,3 pada rpm 180 sebesar 545,68 Nm. Modifikasi model propeller pada 230 rpm menggunakan diameter 1,4 $m$, rake $5^{\circ}$ dan pitch 1,56 merupakan modifikasi yang direkomendasikan untuk memperoleh nilai thrust maksimum sebesar $12076 \mathrm{~N}$, torque 3252,5 Nm dan mendapatkan nilai efisiensi yang paling optimum sebesar 0,7443 .
\end{abstract}

Kata kunci: Kapal Tugboat, Propeller, Diameter, Pitch, Rake

\begin{abstract}
Tugboat is used to pull or push ships which will enter or leave the harbor. To push and pull the ship, a propeller is needed as the ship propulsion. The performance of the propeller on the tugboat is vital for supporting the function of the tugboat. This research will make modifications to the rake, diameter, and pitch of the B-Series propeller on a tugboat using computational methods in order to achieve the best efficiency values. This simulation on this research will make use of Reynold-Averaged Navier Stokes (RANS) equation and describe the turbulent flow using the $k-\varepsilon$ and $k-\omega$. The results of the value torque, thrust, and efficiency that have been simulated will be verified with Wageningan diagram. Wageningen is the characteristics of the B-series propeller that have been published from the experimental results. From the CFD simulation result, it is concluded that the minimum torque is showed in the modification with a rake of $0^{\circ}$, a pitch of 1.36 and a diameter of $1.3 \mathrm{~m}$ at $180 \mathrm{rpm}$ which is 545,68 $\mathrm{Nm}$. Modification of the propeller model $230 \mathrm{rpm}$ using a diameter of $1.4 \mathrm{~m}, 5^{\circ}$ rake and a pitch of 1.56 is the recommended modification to obtain a maximum thrust value of $12076 \mathrm{~N}$, torque of $3252.5 \mathrm{Nm}$ and getting the most optimum efficiency value of 0.7443.
\end{abstract}

Keywords: Tugboat, Propeller, Diameter, Pitch, Rake 


\section{PENDAHULUAN}

Kapal tugboat (tunda) merupakan kapal yang dibangun untuk menarik dan mendorong kapal-kapal yang akan masuk dan keluar pelabuhan. Kapal tugboat juga berperan untuk menarik kapal tongkang, karena tongkang tidak memiliki sistem propulsi. Propeller merupakan mesin penggerak yang digunakan untuk mendorong kapal. Prinsip kerja dari alat propulsi baling-baling adalah gaya dorong pada kapal yang berputar di dalam air dengan digerakkan oleh mesin sehingga mendapatkan gaya angkat atau lifting force yang bekerja pada daun baling-baling [1]. Salah satu aspek yang paling penting dalam pembuatan kapal itu sendiri ialah aspek perencanaan mesin kapal dan perencanaan desain propeller [2]. Hal yang sangat penting dalam perencanaan desain propeller adalah nilai efisiensi dari propeller. Tentu dalam perancangan propeller dipilih nilai efisiensi yang maksimum tanpa terjadinya kavitasi [3]. Dalam perkembangannya propeller mengalami modifikasi bentuk dengan tujuan mendapatkan efisiensi yang paling baik sebagai alat penggerak kapal, salah satu modifikasi itu yaitu skew angle dan blade area ratio (Ae/Ao) [4]. Kecepatan pada kapal tidak terlepas dari desain propeller yang baik agar mendapatkan thrust optimal yang dihasilkan gerak propeller [5]. Tenaga besar yang perlu dihasilkan propeller dengan kecepatan berlayar yang rendah akibat beban kerja yang besar akan memberi dampak penurunan nilai efisiensi dari kinerja propeller yang menyebabkan kinerja kapal menurun. Untuk meningkatkan efisiensi, beberapa penelitian menggunakan end plate pada propeller [6]. Beberapa kriteria khusus pada propeller dapat memberikan gaya dorong yang besar dengan tingkat kebisingan yang rendah, dengan alasan tersebut desain propeller harus memiliki nilai thrust yang besar. Agar mendapatkan nilai tekanan yang rendah dan aliran propeller yang halus dilakukan penelitian tentang sudut kemiringan hub propeller untuk mendapatkan performance yang baik [7]. Terkait dengan permasalah diatas, penelitian ini akan melakukan modifikasi diameter dan pitch propeller B-Series pada kapal tugboat dengan metode komputasi sehingga diperoleh thrust tertinggi, nilai torque terendah dan nilai efficiency yang paling tinggi.

\section{METODOLOGI}

\subsection{Objek Penelitian}

Penelitian ini membutuhkan data primer dan data sekunder. Data primer merupakan data utama dari kapal meliputi Gambar dan ukuran utama pada kapal yaitu linesplan, propeller yang diperoleh data dari PT. PELINDO III Surabaya KT. Subali I. Data sekunder merupakan sumber data yang diperoleh dapat melalui media internet yaitu jurnal-jurnal yang berkaitan dengan penelitian, media buku pembelajaran, e-book media software yang digunakan untuk menambah wawasan dan ilmu,sebagai referensi dalam pengerjaannya, dan sebagai media untuk mencari solusi dari permasalahan yang akan dialami.

\subsection{Variabel Penelitian}

Kapal tugboat KT.Subali di PT. PELINDO III Surabaya digunakan untuk memasukkan dan mengeluarkan kapal-kapal di pelabuhan. Pada Tabel 1 dan Tabel 2 menunjukkan ukuran utama kapal dan ukuran propeller sebagai objek pada penelitian ini.

Tabel 1. Ukuran Utama Kapal Tug Boat

\begin{tabular}{llc}
\hline No & Ukuran utama & Dimensi \\
\hline 1 & Length of Overall & $27,75 \mathrm{~m}$ \\
2 & Length of Waterline & $24,30 \mathrm{~m}$ \\
3 & Length Between Perpendicular & $24,30 \mathrm{~m}$ \\
4 & Breadth & $8,60 \mathrm{~m}$ \\
5 & Height & $3,50 \mathrm{~m}$ \\
6 & Draught & $2,70 \mathrm{~m}$ \\
7 & Vs & $10 \mathrm{knot}$ \\
8 & $\mathrm{Cb}$ & 0,55 \\
\hline
\end{tabular}


Tabel 2. Ukuran Utama Propeller

\begin{tabular}{llc}
\hline No & Ukuran utama & Dimensi \\
\hline 1 & Diameter & $1,3 \mathrm{~m}$ \\
2 & Pitch ratio & 1,2 \\
3 & Pitch $(\mathrm{m})$ & 1,56 \\
4 & Blade number & 4 \\
5 & RPM & $210 \mathrm{rpm}$ \\
\hline
\end{tabular}

Penelitian ini melakukan variasi pada diameter, rake $\left(0^{\circ} ; 2^{\circ} ; 5^{\circ}\right)$, diameter $(1,2 ; 1,3 ; 1,4)$ dan pitch $(1,36 ; 1,56 ; 1,76)$ pada propeller kapal tugboat yang memiliki kecepatan dan kondisi yang sama.

\subsection{Lokasi Penelitian}

Penelitian ini dilakukan pada Laboratorium Perencanaan dibantu Komputer menggunakan software Hydrocamp untuk membantu mendesain propeller, Rhinoceros untuk membantu memodelkan propeller, dan CFD untuk menganalisa model propeller.

\subsection{Pembuatan Model}

Penelitian ini menggunakan software Hydrocamp untuk mendesain propeller, dan Rhinoceros untuk memodelkan dan menjadikan propeller menjadi solid. Setelah itu model akan diexport dalam bentuk IGES.

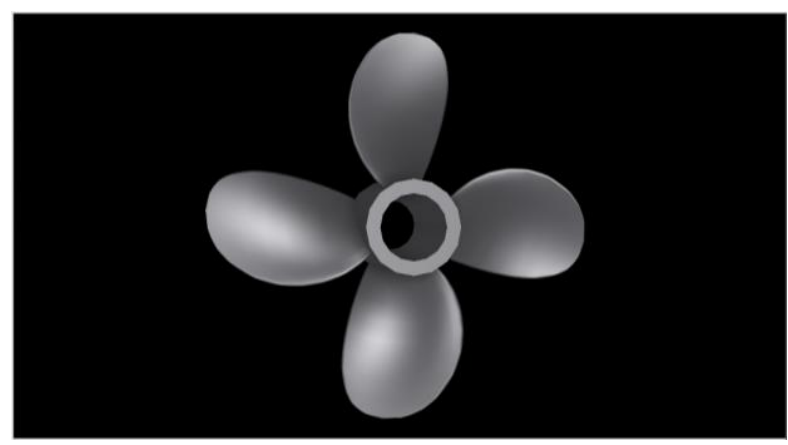

Gambar 1. Model Propeller Kapal Tugboat

\subsection{Validasi Numerik}

Dalam penelitian ini validasi nilai torque, thrust pada model awal dengan perhitungan KT-KQ-J yang terdapat pada grafik Wageningen B-Series propeller dengan nilai $\mathrm{T}$ dan $\mathrm{Q}$ yang diperoleh melalui perhitungan dengan CFD.

\subsection{Pembuatan Model Kapal Tugboat dengan Variasi Rake, Diameter, dan Pitch}

Hasil perhitungan KT-KQ-J di grafik Wegeningen pada model asli valid dengan nilai perhitungan menggunakan CFD maka dilanjutkan dengan memodelkan propeller dengan variasi rake, diameter, dan pitch sehingga memperoleh hasil yang diharapkan.

Tabel 3. Variasi Model Propeller

\begin{tabular}{llll}
\hline No & Rake & Pitch & Diameter \\
\hline 1 & $0^{\varpi}$ & 1,36 & $1,2 \mathrm{~m}$ \\
2 & $2^{\varpi}$ & 1,56 & $1,3 \mathrm{~m}$ \\
3 & $5^{\varpi}$ & 1,76 & $1,4 \mathrm{~m}$ \\
\hline
\end{tabular}

\section{HASIL DAN PEMBAHASAN}

Propeller dari kapal tugboat dibuat menjadi beberapa model agar dapat dianalisa untuk mendapatkan nilai thrust, torque, dan nilai efisiensi maksimum. Model-model propeller dianalisa dengan 
menggunakan metode CFD kemudian akan divalidasi hasil analisa CFD dengan menggunakan perhitungan matematis KT-KQ grafik Wageningen.

Tabel 4. Variasi Model Propeller

\begin{tabular}{llll}
\hline No & Rake & Pitch & Diameter \\
\hline 1 & $0^{\text {ळ }}$ & 1,36 & $1,2 \mathrm{~m}$ \\
2 & $2^{\text {ब }}$ & 1,56 & $1,3 \mathrm{~m}$ \\
3 & $5^{\varpi}$ & 1,76 & $1,4 \mathrm{~m}$ \\
\hline
\end{tabular}

\subsection{Model Propeller}

Tabel 5. Ukuran Utama Propeller

\begin{tabular}{llc}
\hline No & Ukuran utama & Dimensi \\
\hline 1 & Diameter & $1,3 \mathrm{~m}$ \\
2 & Pitch ratio & 1,2 \\
3 & Pitch $(\mathrm{m})$ & 1,56 \\
4 & Blade number & 4 \\
5 & RPM & $210 \mathrm{rpm}$ \\
\hline
\end{tabular}

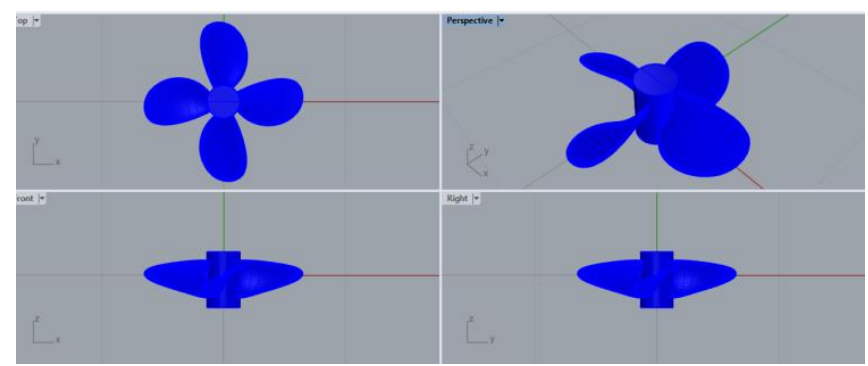

Gambar 2. Pembuatan Model Propeller

Tabel 5 merupakan Ukuran utama propeller kapal yang digunakan untuk pembuatan propeller melalui software hydrocamp. Pada Gambar 2 merupakan model 3D propeller kapal tugboat menggunakan aplikasi Rhinoceros. Kemudian model tersebut di-export dalam bentuk IGS sehingga dapat dibuka oleh software yang digunakan dalam metode CFD.

\subsection{Simulasi CFD (Computational Fluid Dynamic)}

\subsubsection{Geometry}

Tahap geometry merupakan tahap untuk menentukan model yang akan dianalisa dengan software CFD. Pada tahap geometry, model dari Rhinoceros dapat dilakukan pengecekan apakah model sudah solid atau belum.

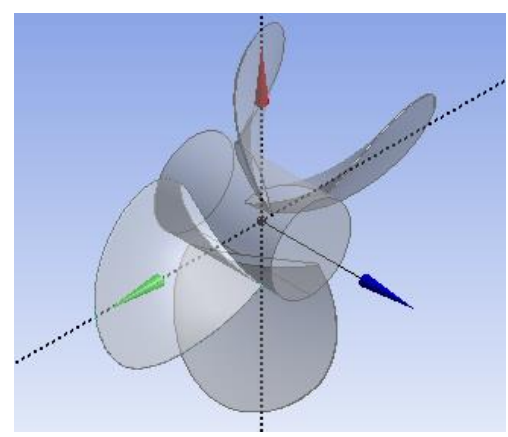

\section{Gambar 3. Model Propeller pada Metode Komputasi}

Langkah berikutnya adalah pembuatan interface pada propeller dengan cara mengklik enclosure pada menu tools. 


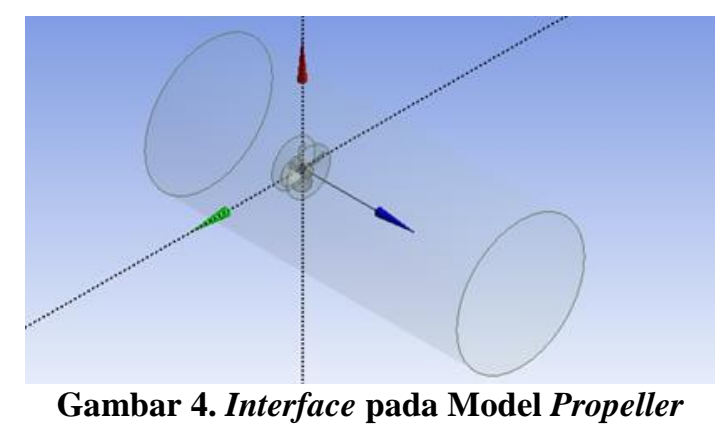

Kemudian, pembagian tugas antara boundary dan benda dengan menggunakan boolean dengan cara mengklik create lalu Boolean, di menu operation dipilih substract kemudian muncul menu tool bodies dan target bodies. Pada tool bodies dipilih propeller kapal dan pada target bodies dipilih interface. Kemudian klik yes. Selanjutnya yang terakhir pada tahap geometry adalah penamaan pada setiap bagian propeller dan interface. Adapun penamaannya yaitu : propeller, interface, inlet, outlet, dan wall. Caranya klik pada setiap part lalu klik kanan mouse pilih named selection kemudian isi sesuai dengan nama part propeller, interface, dan wall.

\subsubsection{Meshing}

Langkah selanjutnya setelah boundary building atau domain fluida adalah proses meshing pada propeller. Perlu diperhatikan bahwa jumlah elemen akan terbentuk lebih banyak bila ukuran elemen tersebut semakin kecil dan waktu pada proses running lebih lama dan file yang dihasilkan lebih besar.

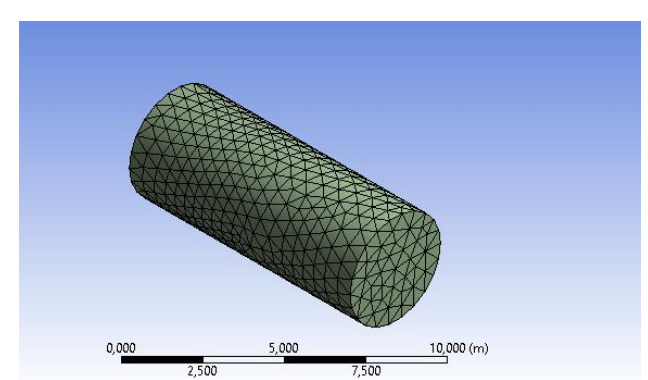

Gambar 5. Mesh Pada Model Propeller

\subsubsection{Set $U p$}

Set up merupakan tahap untuk mengatur domain, interfaces, boundary, solution unit, dan solver control yang sangat diperlukan untuk mendapatkan grafik dan hasil di tahap solution dan result.

Tabel 6. Set Up

\begin{tabular}{lcc}
\hline \multicolumn{1}{c}{ Domain - Default Domain } \\
\hline \multicolumn{1}{c}{ Location } & Fluid \\
& Materials & \\
& Water & \\
\hline Fluid Definition & Material Library \\
Morphology & Continuous Fluid \\
& \\
Buoyancy Model & Settings & Non Buoyant \\
Morphology & Rotating \\
Angular Velocity & $-1.800 e+$ O2 [rev min $\left.{ }^{\wedge}-1\right]$ \\
Axis Definition & Coordinate Axis \\
Rotation Axis & Global X \\
Reference Pressure & 1.0000e+00 [atm] \\
Heat Transfer Model & None \\
Turbulence Model & k epsilon \\
Turbulent Wall Functions & Scalable \\
\hline
\end{tabular}

Rekayasa Hijau - 67 
Pada solver control dipilih eror 0,0001 agar nilai yang diperoleh memiliki persentase tingkat eror yang sangat kecil.

\subsubsection{Solution}

Kemudian setelah pengerjaan langkah pre-processor selesai yang dilakukan selanjutnya adalah ke tahap solution. Pada tahap ini akan dilakukan perhitungan berupa iterasi dan akan diperoleh grafik.

\subsubsection{Result}

Setelah perhitungan pada tahap solution selesai maka hasil berupa thrust dan torque dapat diperoleh pada tahap result.

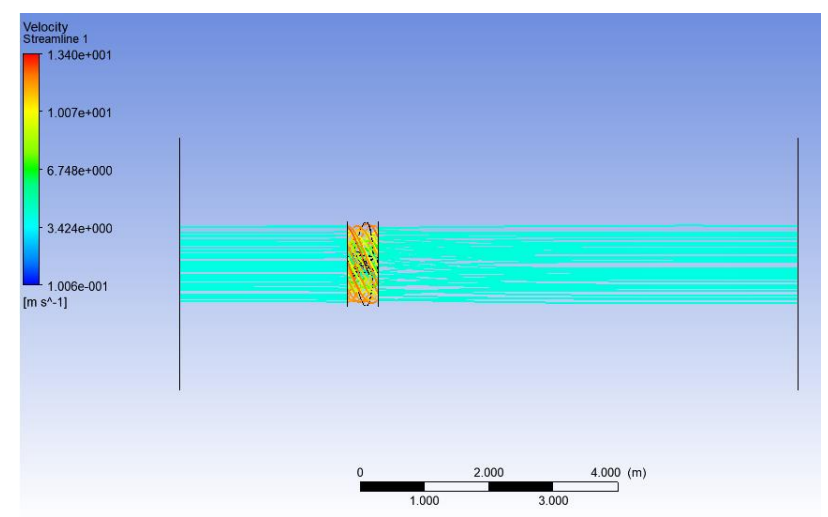

Gambar 6. Tahap Result

\subsection{Hasil Analisa CFD Thrust dan Torque pada Model Propeller Asli}

Hasil yang diperoleh dari perhitungan menggunakan bantuan CFD pada model asli propeller diperoleh nilai thrust 43388, $1 \mathrm{pdl}=5998,4 \mathrm{~N}$, nilai torque $45650,4 \mathrm{ft} p d l=1923,71 \mathrm{Nm}$, dan nilai effisiensi 0,5655 .

\subsection{Validasi}

Penelitian ini melakukan perbandingan hasil yang diperoleh melalui perhitungan CFD dengan perhitungan rumus data B-Series KT-KQ Wageningen [8], yakni sebagai berikut :

$$
\begin{gathered}
K_{T}=\frac{T}{\rho n^{2} D^{4}} \\
K_{Q}=\frac{Q}{\rho n^{2} D^{5}} \\
\mathrm{~J}=\frac{V G}{n x D} \\
\eta_{Q}=\frac{T x V Q}{2 x \pi x Q x n} \\
w=0,5 x C b-0,05 \\
\mathrm{Va}=(1-\mathrm{w}) \mathrm{Vs}
\end{gathered}
$$


Keterangan :

$\mathrm{KT}=$ Koefisien gaya dorong baling-baling

KQ $\quad$ Koefisien torsi baling-baling

$\mathrm{J}=$ Koefisien advanced baling-baling

$\mathrm{Va} \quad=$ kecepatan advanced, $\mathrm{ft} / \mathrm{s}$

$\mathrm{D}=$ diameter propeller, $\mathrm{ft}$

$\mathrm{N} \quad=$ putaran propeller, rev $/ \mathrm{s}$

$\mathrm{T} \quad=$ thrust propeller,, $\mathrm{bf}$

$\mathrm{Q} \quad=$ torque propeller, $\mathrm{lbf} \mathrm{ft}$

$\rho \quad=$ =massa jenis fluida (fluid density), $1,9905 \mathrm{~s} / \mathrm{ft} 3$

Dimensi Propeller :

$$
\begin{array}{ll}
\mathrm{D} & =1,3 \mathrm{~m}=4,27 \mathrm{ft} \\
\mathrm{P} & =1,2 \\
\mathrm{Vs} & =10 \mathrm{knot}=16,88 \mathrm{ft} / \mathrm{s}=3,986784 \mathrm{~m} / \mathrm{s} \\
\mathrm{N} & =210 \mathrm{rpm}=3,5 \mathrm{rps} \\
\rho & =1,99 \mathrm{~s} / \mathrm{ft}^{3} \\
\text { BAR } & =0,6 \\
\text { Type } & =\text { B-Series }
\end{array}
$$

Perhitungan Wake Friction (w) and Velocity advance (Va)

$$
\begin{array}{ll}
\mathrm{w}=0,5(\mathrm{CB})-0,05 & \mathrm{Va}=(1-\mathrm{w}) \mathrm{Vs} \\
\mathrm{w}=0,5(0,55)-0,05 & \mathrm{Va}=(1-0,225) \times 16,88 \\
\mathrm{w}=0,225 & \mathrm{Va}=13,08 \mathrm{ft} / \mathrm{s}
\end{array}
$$

Perhitungan thrust, torque dan efficiency propeller

$$
\mathrm{J}=\frac{V \mathrm{~V}}{\mathrm{nxD}}=\frac{13,0 \mathrm{~g}}{3,5 \times 4,27}=0,88
$$

Dari nilai J ( koefisien advanced) diperoleh nilai KT-KQ dari grafik wageningen [8]

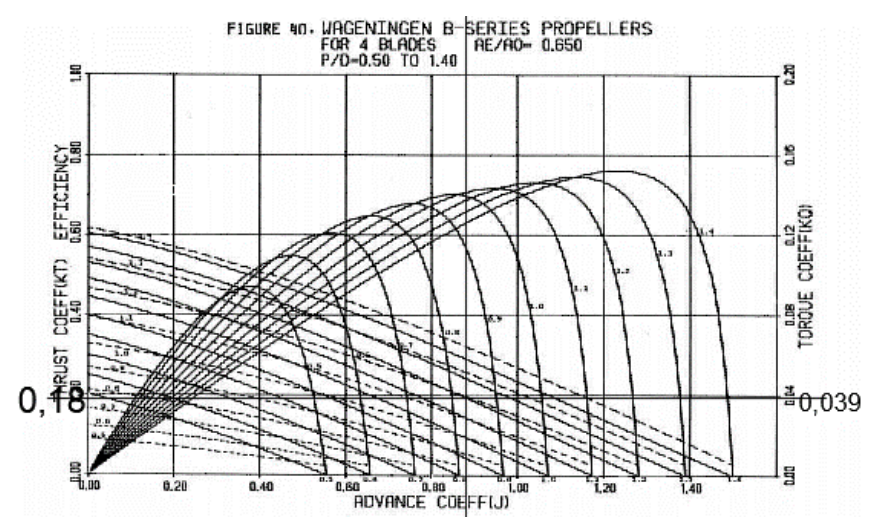

Gambar 7. Grafik Wageningen [8]

Dari grafik diperoleh :

$$
\begin{aligned}
& \mathrm{KT}=0,18 \\
& \mathrm{KQ}=0,039 \\
& K_{T}=\frac{r}{\rho n^{2} D^{4}} \\
& \mathrm{~T}=K_{T} \rho n^{2} D^{4}=0,18 \times 1,99\left(\mathrm{~s} / \mathrm{ft}^{3}\right) \times 3,5^{2}(\mathrm{rps}) \times 4,27^{4}(\mathrm{ft})=6488,73 \mathrm{~N}
\end{aligned}
$$




$$
\begin{aligned}
& \mathrm{Q}=K_{Q} \rho n^{2} D^{5}=0,039 \times 1,99\left(\mathrm{~s} / \mathrm{ft}^{3}\right) \times 3,5^{2}(\mathrm{rps}) \times 4,27^{5}(\mathrm{ft})=1835,41 \mathrm{Nm}
\end{aligned}
$$

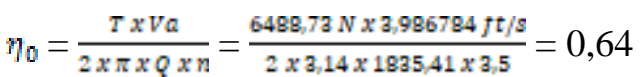

Tabel 6. Perbandingan nilai thrust yang diperoleh dengan CFD dan perhitungan data B4-Series

\begin{tabular}{lllll}
\hline Variabel & CFD & $\begin{array}{l}\text { Perhitungan } \\
\text { B-Series }\end{array}$ & Data & Error \\
\hline Thrust & $5998,4 \mathrm{~N}$ & $6488,73 \mathrm{~N}$ & $7,556 \%$ \\
Torque & $1923,71 \mathrm{Nm}$ & $1835,41 \mathrm{Nm}$ & $4,8113 \%$ \\
Efficiency & 0,5655 & 0,64 & $10 \%$ \\
\hline
\end{tabular}

Dalam perhitungan validasi menggunakan diagram perhitungan thrust (force) dan torque pada propeller dengan metode perhitungan matematis sesuai dengan rumus pada diagram KT-KQ-J. Secara umum karakteristik dari baling-baling kapal pada kondisi open water test adalah seperti yang dipresentasikan pada diagram KT-KQ-J ditunjukkan pada Tabel 6.

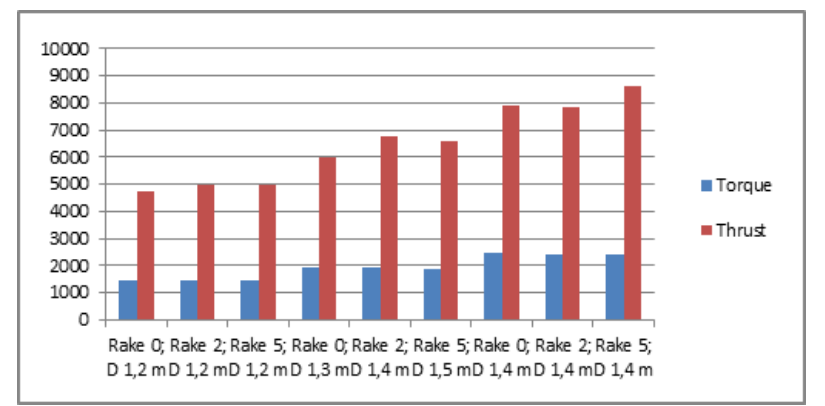

Gambar 8. Hasil Perhitungan Thrust dan Torque dengan

Variasi Rake dan Diameter pada Propeller pada RPM 210

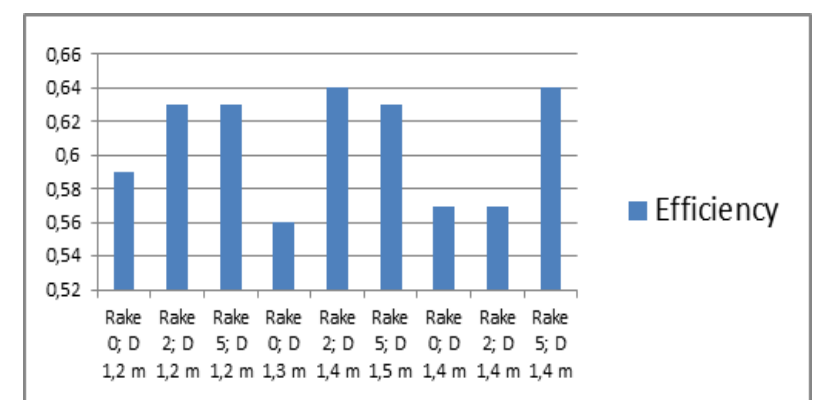

Gambar 9. Hasil Perhitungan Efisiensi dengan Variasi

Rake dan Diameter pada Propeller pada RPM 210

Gambar 8 dan 9 menunjukkan hasil dari modifikasi rake dan modifikasi diameter. Bila ditinjau dari variasi rake pada masing-masing diameter, dapat diberikan kesimpulan bahwa pada kasus ini yaitu rake $0^{\circ}, 2^{\circ}$, dan $5^{\circ}$ pada diameter yang sama tidak terlalu memberikan pengaruh pada kenaikan maupun penurunan dari thrust dan torque. Ditinjau dari variasi diameter, dengan rake yang sama nilai thrust dan torque akan mengalami kenaikan sesuai dengan rumus perhitungan dari data Wageningen. Pada kecepatan 210 rpm diperoleh thrust terbesar yakni 8603,1 $\mathrm{N}$ dan nilai effisiensi 0,64. 


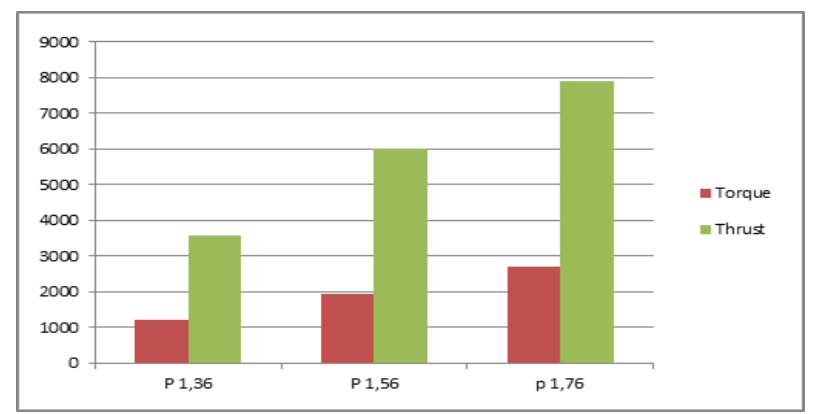

Gambar 10. Hasil Perhitungan Thrust dan Torque dengan Variasi Pitch pada Propeller pada RPM 210

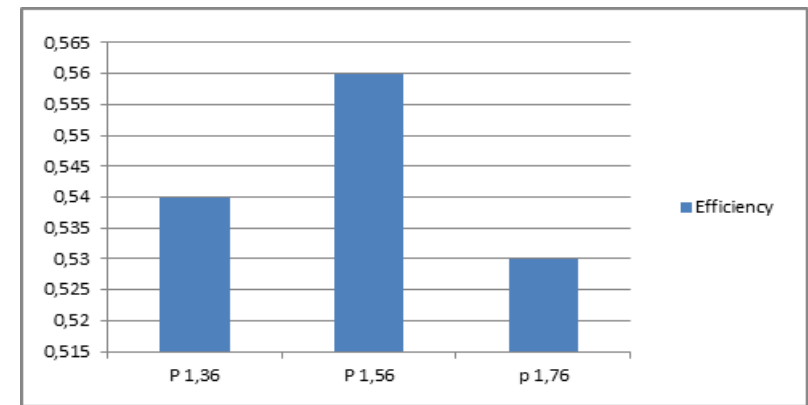

Gambar 11. Hasil Perhitungan Efficiency dengan Variasi Pitch pada Propeller pada RPM 210

Gambar 10 dan 11 menunjukkan hasil dari modifikasi pitch. Melalui Tabel diperoleh nilai perhitungan semakin besar pitch propeller maka akan semakin besar pula thrust dan torque propeller. Hal ini sesuai dengan grafik Wageningen diatas semakin besar pitch maka nilai KT-KQ akan semakin besar pula dari hal itu maka thrust dan torque juga akan semakin besar. Sehingga diperoleh nilai thrust dan torque terbesar pada pitch 1,76 yakni 7911,1 N.

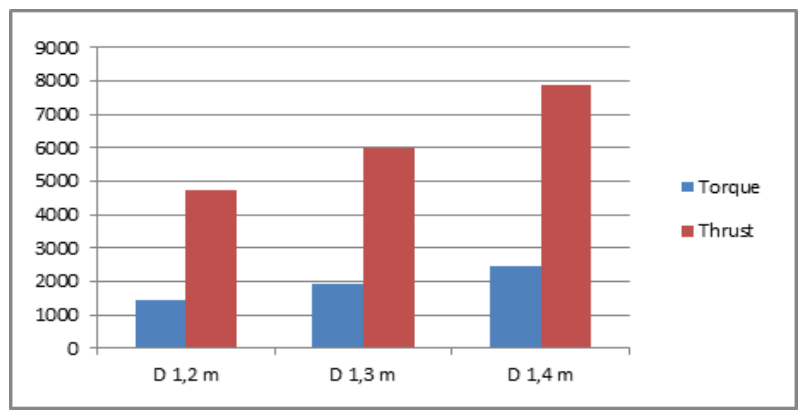

Gambar 12. Hasil Perhitungan Thrust dan Torque dengan

Variasi Diameter pada Propeller pada RPM 210

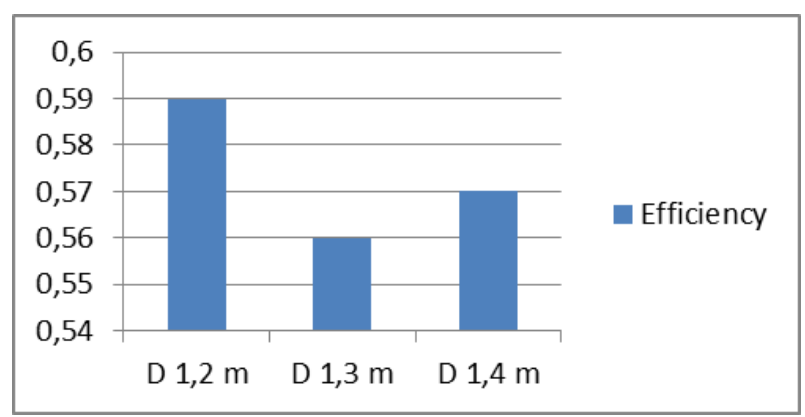

Gambar 13. Hasil Perhitungan Efficiency dengan

Variasi Diameter pada Propeller pada RPM 210 
Gambar 12 dan 13 menunjukkan hasil dari modifikasi diameter. Melalui Tabel diperoleh nilai perhitungan semakin besar diameter propeller maka akan semakin besar pula thrust dan torque propeller. Hal ini sesuai dengan rumus perhitungan data grafik Wageningen yaitu $\mathrm{T}=\mathrm{KT} \mathrm{\rho n}^{\wedge} 2 \mathrm{D}^{\wedge} 4$. Sehingga diperoleh nilai thrust terbesar melalui perhitungan CFD pada diameter 1,4 m yakni 7887,4 N.

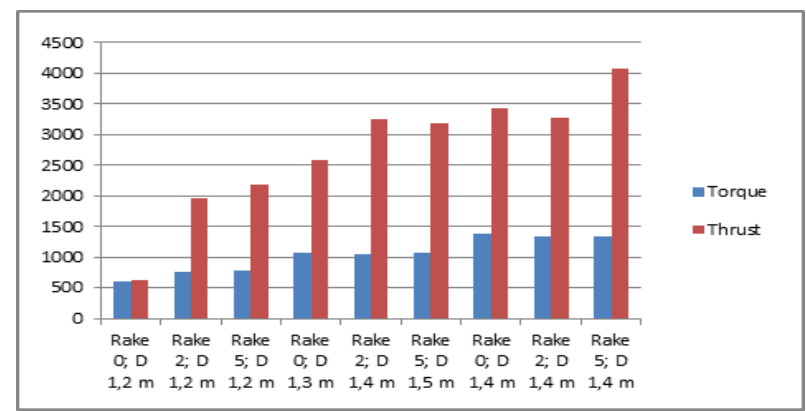

Gambar 14. Hasil Perhitungan Thrust dan Torque dengan Variasi Rake dan Diameter pada Propeller pada RPM 180

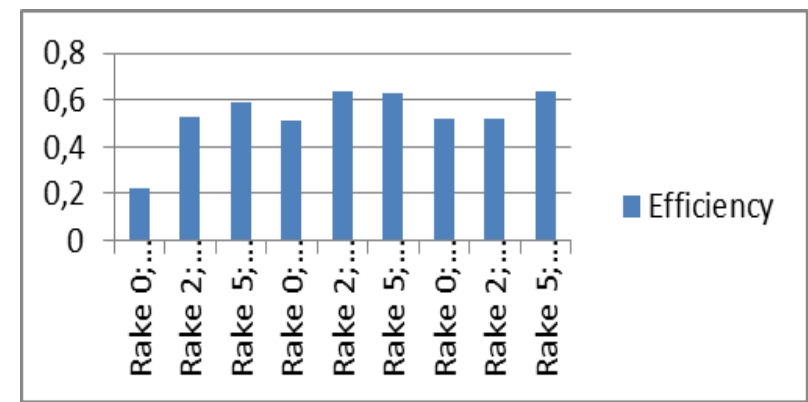

Gambar 15. Hasil Perhitungan Efficiency dengan

Variasi Rake dan Diameter pada Propeller pada RPM 180

Gambar 14 dan 15 menunjukkan hasil dari modifikasi rake dan modifikasi diameter. Bila ditinjau dari variasi rake pada masing-masing diameter, dapat diberikan kesimpulan bahwa pada kasus ini yaitu rake $0^{\circ}, 2^{\circ}$, dan $5^{\circ}$ pada diameter yang sama tidak terlalu memberikan pengaruh pada kenaikan maupun penurunan dari thrust dan torque. Ditinjau dari variasi diameter, dengan rake yang sama nilai thrust dan torque akan mengalami kenaikan sesuai dengan rumus perhitungan dari data Wageningen. Pada kecepatan $180 \mathrm{rpm}$ diperoleh thrust terbesar yakni 4064,578 $\mathrm{N}$ dan nilai effisiensi 0,64 . Nilai thrust pada rpm 180 lebih rendah dibandingkan nilai thrust $210 \mathrm{rpm}$ yakni 8603,1 $\mathrm{N}$ dikarenakan rpm berbanding lurus dengan thrust dilihat dari rumus data Wageningen yakni $\mathrm{T}=\mathrm{KT} \rho \mathrm{n}^{\wedge} 2 \mathrm{D}^{\wedge} 4$.

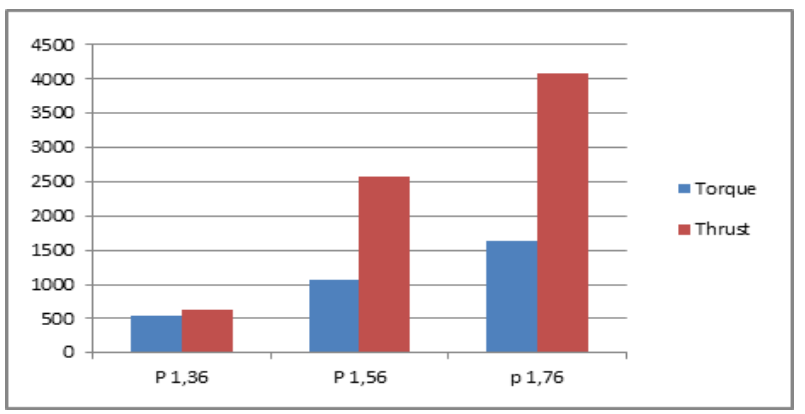

Gambar 16. Hasil Perhitungan Thrust dan Torque dengan Variasi Pitch pada Propeller pada RPM 180 


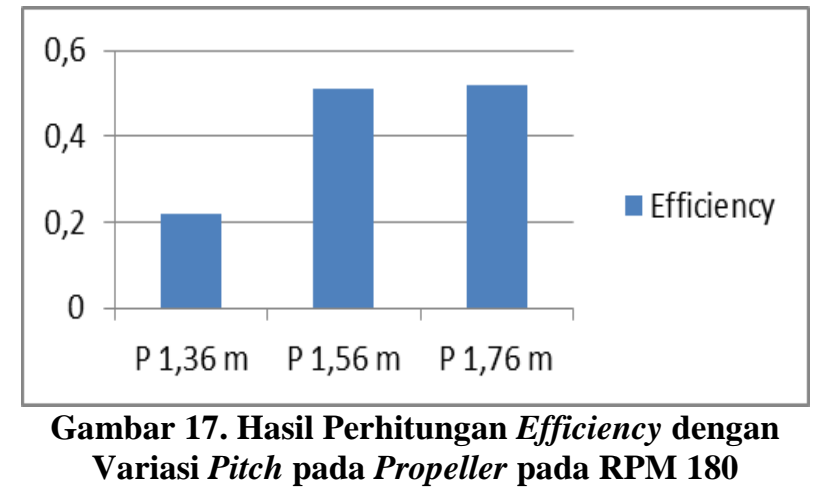

Gambar 16 dan 17 menunjukkan hasil dari modifikasi pitch. Melalui Tabel diperoleh nilai perhitungan semakin besar pitch propeller maka akan semakin besar pula thrust dan torque propeller. Hal ini sesuai dengan grafik Wageningen diatas semakin besar pitch maka nilai KT-KQ akan semakin besar pula dari hal itu maka thrust dan torque juga akan semakin besar. Sehingga diperoleh nilai thrust dan torque terbesar pada pitch 1,76 yakni 4085,43 N. Nilai thrust pada rpm 180 lebih rendah dibandingkan nilai thrust $210 \mathrm{rpm}$ pada variasi pitch yakni 7911,1 N dikarenakan rpm berbanding lurus dengan thrust dilihat dari rumus data Wageningen yakni $\mathrm{T}=\mathrm{KT} \rho \mathrm{n}^{\wedge} 2 \mathrm{D}^{\wedge} 4$.

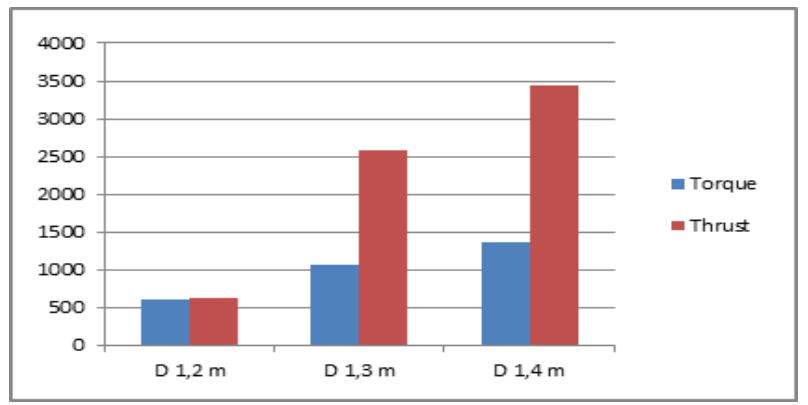

Gambar 18. Hasil Perhitungan Thrust dan Torque dengan Variasi Diameter pada Propeller pada RPM 180

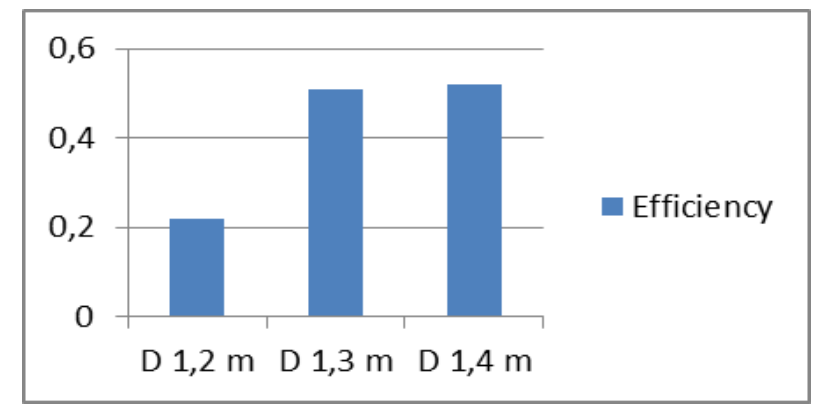

Gambar 19. Hasil Perhitungan Efficiency dengan
Variasi Diameter pada Propeller pada RPM 180

Gambar 18 dan 19 menunjukkan hasil dari modifikasi diameter. Melalui Tabel diperoleh nilai perhitungan semakin besar diameter propeller maka akan semakin besar pula thrust dan torque propeller. Hal ini sesuai dengan rumus perhitungan data grafik Wageningen yaitu $\mathrm{T}=\mathrm{KT} \mathrm{\rho n}^{\wedge} 2 \mathrm{D}^{\wedge} 4$. Sehingga diperoleh nilai thrust terbesar melalui perhitungan CFD pada diameter 1,4 m yakni 3435,65 N. Nilai thrust pada rpm 180 lebih rendah dibandingkan nilai thrust 210 rpm yakni 7887,4 N pada variasi diameter dikarenakan rpm berbanding lurus dengan thrust dilihat dari rumus data Wageningen yakni $\mathrm{T}=\mathrm{KT} \rho \mathrm{n}^{\wedge} 2 \mathrm{D}^{\wedge} 4$. 


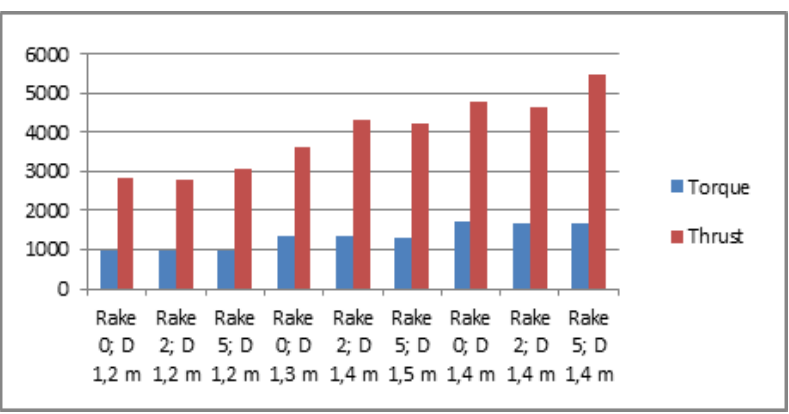

Gambar 20. Hasil Perhitungan Thrust dan Torque dengan

Variasi Rake dan Diameter pada Propeller pada RPM 190

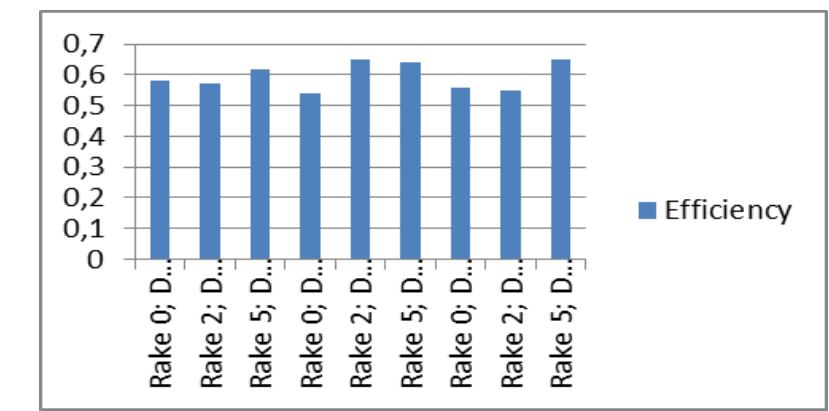

Gambar 21. Hasil Perhitungan Efficiency dengan

Variasi Rake dan Diameter pada Propeller pada RPM 190

Gambar 20 dan 21 menunjukkan hasil dari modifikasi pitch. Melalui Tabel diperoleh nilai perhitungan semakin besar pitch propeller maka akan semakin besar pula thrust dan torque propeller. Hal ini sesuai dengan grafik Wageningen diatas semakin besar pitch maka nilai KT-KQ akan semakin besar pula dari hal itu maka thrust dan torque juga akan semakin besar. Sehingga diperoleh nilai thrust dan torque terbesar pada pitch 1,76 yakni 5283,058 N. Nilai thrust pada rpm 190 lebih tinggi dibandingkan nilai thrust $180 \mathrm{rpm}$ pada variasi pitch yakni 4085,43 $\mathrm{N}$ dikarenakan rpm berbanding lurus dengan thrust dilihat dari rumus data Wageningen yakni $\mathrm{T}=\mathrm{KT} \rho \mathrm{n}^{\wedge} 2 \mathrm{D}^{\wedge} 4$.

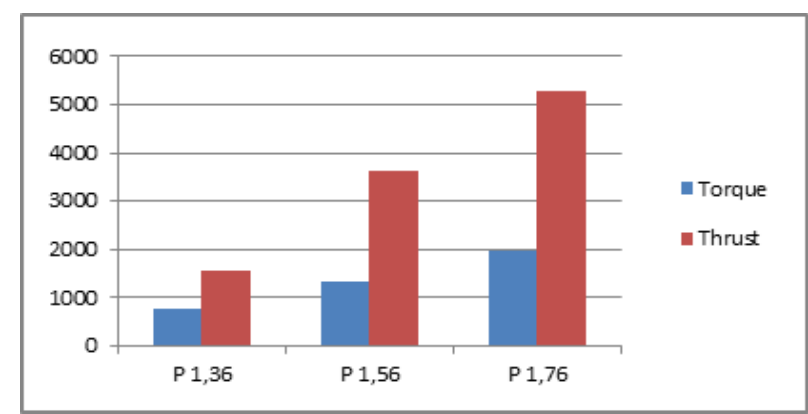

Gambar 22. Hasil Perhitungan Thrust dan Torque dengan Variasi Pitch pada Propeller pada RPM 190

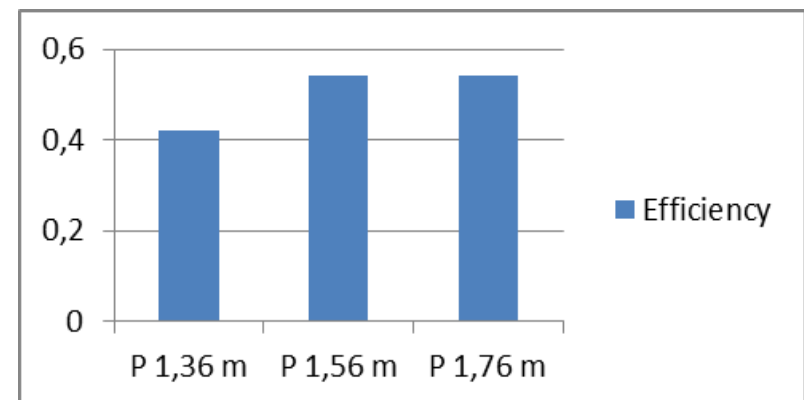

Gambar 23. Hasil Perhitungan Efficiency dengan Variasi Pitch pada Propeller pada RPM 190 
Gambar 22 dan 23 menunjukkan hasil dari modifikasi pitch. Melalui Tabel diperoleh nilai perhitungan semakin besar pitch propeller maka akan semakin besar pula thrust dan torque propeller. Hal ini sesuai dengan grafik Wageningen diatas semakin besar pitch maka nilai KT-KQ akan semakin besar pula dari hal itu maka thrust dan torque juga akan semakin besar. Sehingga diperoleh nilai thrust dan torque terbesar pada pitch 1,76 yakni 5283,058 N. Nilai thrust pada rpm 190 lebih tinggi dibandingkan nilai thrust $180 \mathrm{rpm}$ pada variasi pitch yakni 4085,43 $\mathrm{N}$ dikarenakan rpm berbanding lurus dengan thrust dilihat dari rumus data Wageningen yakni $\mathrm{T}=\mathrm{KT} \rho \mathrm{n}^{2} \mathrm{D}^{4}$.

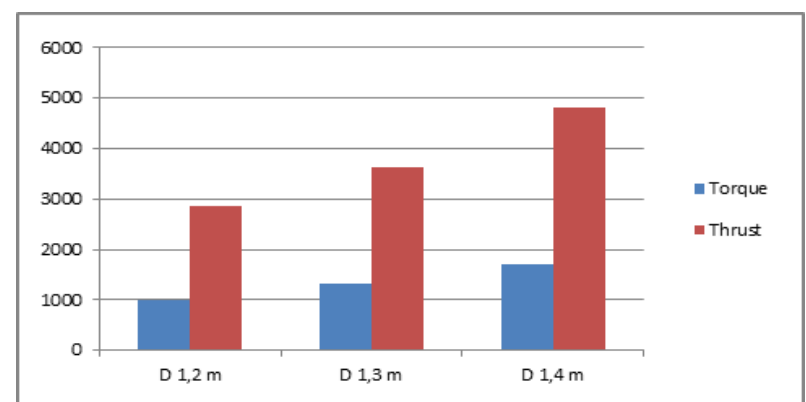

\section{Gambar 24. Hasil Perhitungan Thrust dan Torque dengan Variasi Diameter pada Propeller pada RPM 190}

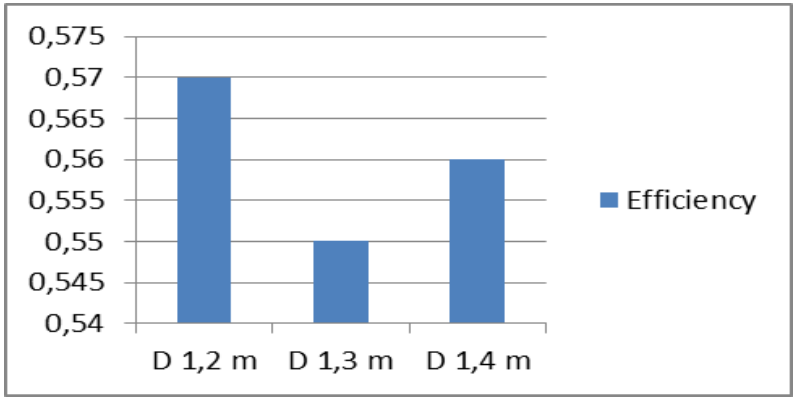

Gambar 25. Hasil Perhitungan Efficiency dengan

Variasi Diameter pada Propeller pada RPM 190

Gambar 24 dan 25 menunjukkan hasil dari modifikasi diameter. Melalui Tabel diperoleh nilai perhitungan semakin besar diameter propeller maka akan semakin besar pula thrust dan torque propeller. Hal ini sesuai dengan rumus perhitungan data grafik Wageningen yaitu $T=K T \rho n^{2} D^{4}$. Sehingga diperoleh nilai thrust terbesar melalui perhitungan CFD pada diameter 1,4 m yakni 4806,289 $\mathrm{N}$. Nilai thrust pada rpm 190 lebih tinggi dibandingkan nilai thrust $180 \mathrm{rpm}$ pada variasi diameter propeller yakni $3425,65 \mathrm{~N}$ pada variasi diameter dikarenakan rpm berbanding lurus dengan thrust dilihat dari rumus data Wageningen yakni $\mathrm{T}=\mathrm{KT} \rho \mathrm{n}^{\wedge} 2 \mathrm{D}^{\wedge} 4$.

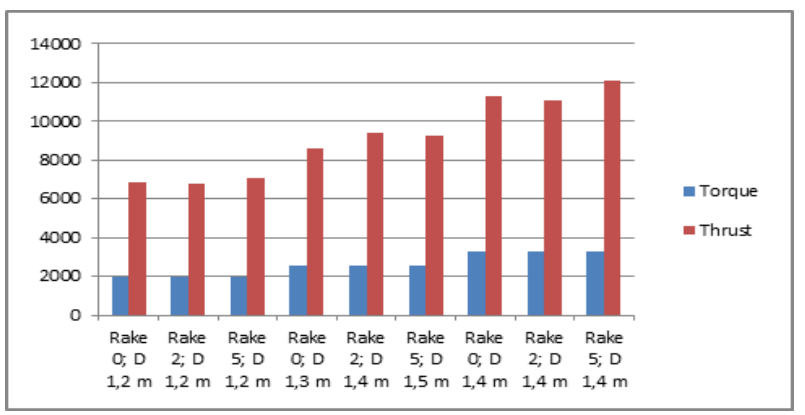

Gambar 26. Hasil Perhitungan Thrust dan Torque dengan Variasi Rake dan Diameter pada Propeller pada RPM 230 


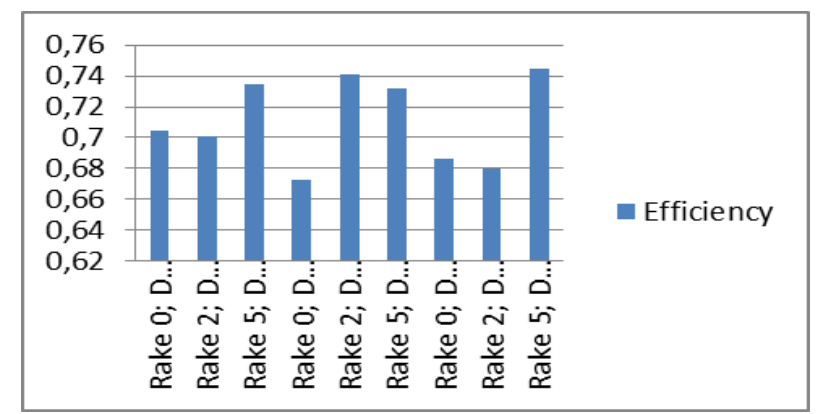

Gambar 27. Hasil Perhitungan Efficiency dengan

Variasi Rake dan Diameter pada Propeller pada RPM 230

Gambar 26 dan 27 menunjukkan hasil dari modifikasi rake dan modifikasi diameter. Bila ditinjau dari variasi rake pada masing-masing diameter, dapat diberikan kesimpulan bahwa pada kasus ini yaitu rake $0^{\circ}, 2^{\circ}$, dan $5^{\circ}$ pada diameter yang sama tidak terlalu memberikan pengaruh pada kenaikan maupun penurunan dari thrust dan torque. Ditinjau dari variasi diameter, dengan rake yang sama nilai thrust dan torque akan mengalami kenaikan sesuai dengan rumus perhitungan dari data Wageningen. Pada kecepatan $230 \mathrm{rpm}$ diperoleh thrust terbesar yakni $12076 \mathrm{~N}$ dan nilai effisiensi 0,7443. Nilai thrust pada rpm 230 lebih besar dibandingkan nilai thrust $190 \mathrm{rpm}$ yakni 5478,806 N dikarenakan rpm berbanding lurus dengan thrust dilihat dari rumus data Wageningen yakni $\mathrm{T}=\mathrm{KT} \rho \mathrm{n}^{2} \mathrm{D}^{4}$.

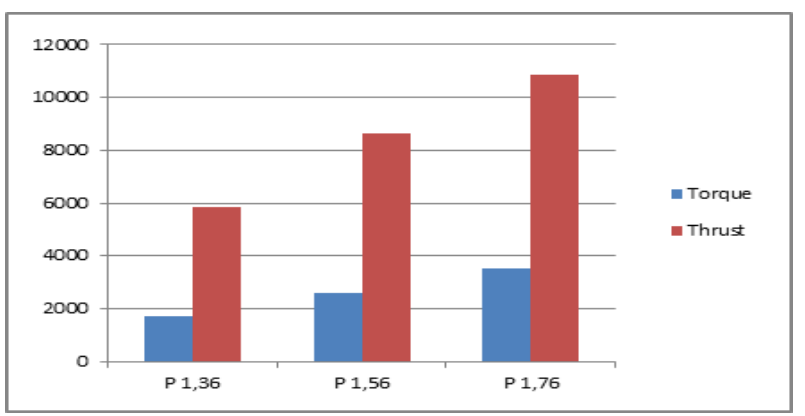

Gambar 28. Hasil Perhitungan Thrust dan Torque dengan Variasi Pitch pada Propeller pada RPM 230

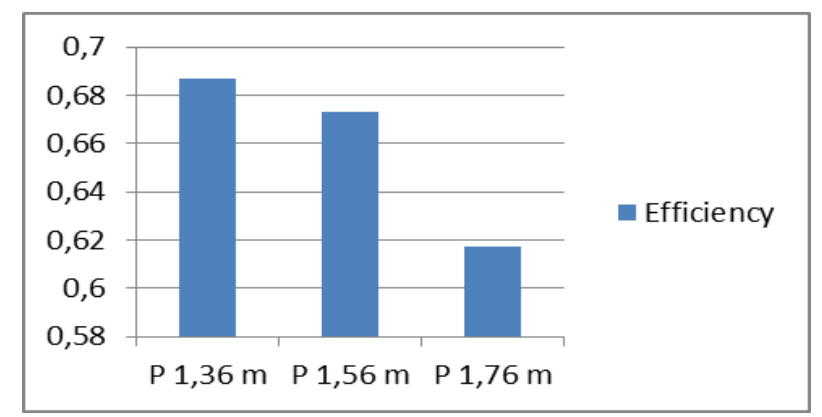

Gambar 29. Hasil Perhitungan Efficiency dengan

Variasi Pitch pada Propeller pada RPM 230

Gambar 28 dan 29 menunjukkan hasil dari modifikasi pitch. Melalui Tabel diperoleh nilai perhitungan semakin besar pitch propeller maka akan semakin besar pula thrust dan torque propeller. Hal ini sesuai dengan grafik Wageningen diatas semakin besar pitch maka nilai KT-KQ akan semakin besar pula dari hal itu maka thrust dan torque juga akan semakin besar. Sehingga diperoleh nilai thrust dan torque terbesar pada pitch 1,76 yakni $10835 \mathrm{~N}$. Nilai thrust pada rpm 230 lebih tinggi dibandingkan nilai thrust $190 \mathrm{rpm}$ pada variasi pitch yakni 5283,058 N dikarenakan rpm berbanding lurus dengan thrust dilihat dari rumus data Wageningen yakni $\mathrm{T}=\mathrm{KT} \rho \mathrm{n}^{2} \mathrm{D}^{4}$. 


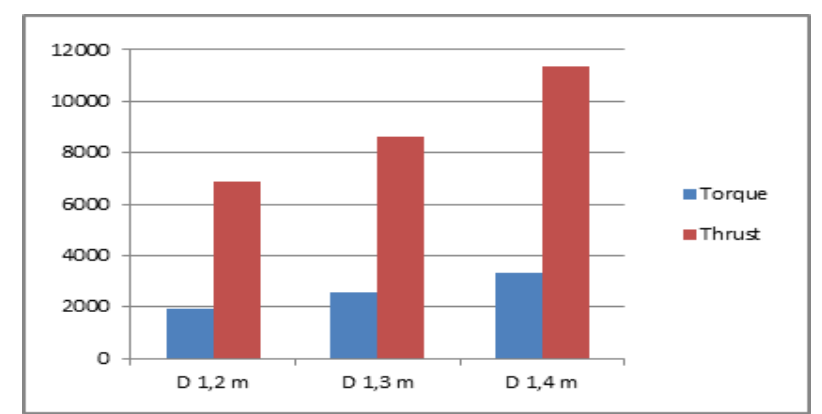

Gambar 30. Hasil Perhitungan Thrust dan Torque dengan Variasi Diameter pada Propeller pada RPM 230

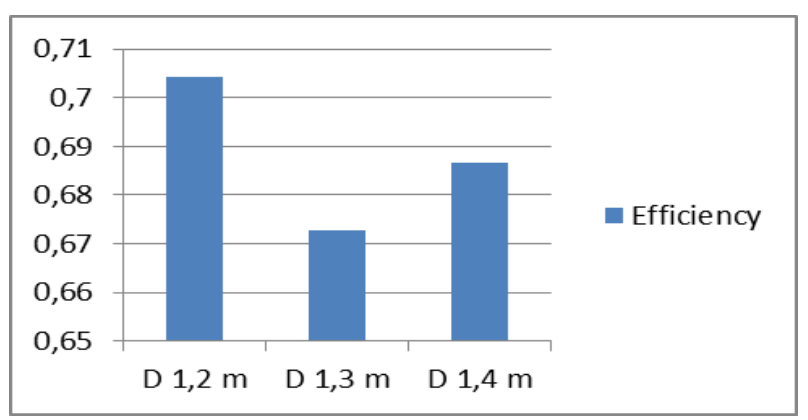

Gambar 31. Hasil Perhitungan Efficiency dengan Variasi Diameter pada Propeller pada RPM 230

Gambar 30 dan 31 menunjukkan hasil dari modifikasi diameter. Melalui Tabel diperoleh nilai perhitungan semakin besar diameter propeller maka akan semakin besar pula thrust dan torque propeller. Hal ini sesuai dengan rumus perhitungan data grafik Wageningen yaitu $\mathrm{T}=\mathrm{KT} \rho \mathrm{n}^{2} \mathrm{D}^{4}$. Sehingga diperoleh nilai thrust terbesar melalui perhitungan CFD pada diameter $1,4 \mathrm{~m}$ yakni $11330 \mathrm{~N}$. Nilai thrust pada rpm 230 lebih tinggi dibandingkan nilai thrust $190 \mathrm{rpm}$ pada variasi diameter propeller yakni 4806,289 $\mathrm{N}$ pada variasi diameter dikarenakan rpm berbanding lurus dengan thrust dilihat dari rumus data Wageningen yakni $\mathrm{T}=\mathrm{KT} \rho \mathrm{n}^{2} \mathrm{D}^{4}$.

\subsection{Kesimpulan}

\section{KESIMPULAN}

Dari hasil analisa diperoleh juga kesimpulan sebagai berikut

1. Dari hasil analisa diperoleh bahwa nilai diameter dan pitch sebuah propeller sangat mempengaruhi nilai thrust dan torque. Semakin besar diameter dan pitch maka nilai thrust dan torque akan semakin besar. Hal tersebut diperoleh karena melalui rumus perhitungan data BSeries pada grafik wageningen $\mathrm{T}=\mathrm{KT} \rho \mathrm{n}^{\wedge} 2 \mathrm{D}^{\wedge} 4$ dan $\mathrm{Q}=\mathrm{KQ} \rho \mathrm{n}^{\wedge} 2 \mathrm{D}^{\wedge} 5$. Nilai rake tidak terlalu mempunyai pengaruh terhadap nilai thrust dan torque propeller karena nilai yang diperoleh dari hasil analisa tidak terus menerus mengalami kenaikan maupun penurunan pada variasi rake $0^{\circ}, 2^{\circ}, 5^{\circ}$. Dari hasil analisa diperoleh nilai thrust terbesar pada model rake $5^{\circ}$, pitch 1,56 , dan diameter 1,4 m pada kecepatan 230 rpm yakni $12076 \mathrm{~N}$.

2. Hasil variasi kecepatan yaitu semakain besar kecepatan kapal maka semakin besar nilai thrust dan torque dari sebuah propeller. Dilihat dari Tabel 20-22 yakni dengan kecepatan 230 rpm diperoleh nilai thrust yang lebih besar dari pada nilai thrust dan torque di Tabel 11-19 yang kecepatannya $180 \mathrm{rpm}, 190 \mathrm{rpm}$, dan $210 \mathrm{rpm}$. Nilai thrust terbesar diperoleh pada model $5^{\circ}$, pitch 1,56, dan diameter 1,4 m pada kecepatan 230 rpm yakni $12076 \mathrm{~N}$.

3. Nilai diameter propeller sebesar $1,4 \mathrm{~m}$, rake $5^{\circ}$, pitch 1,56 , dan kecepatan sebesar $230 \mathrm{rpm}$ merupakan modifikasi model propeller yang paling tepat untuk memperoleh nilai thrust maksimum yaitu $12076 \mathrm{~N}$, torque 3252,5 Nm dan efisiensi optimum sebesar 0,7443 


\subsection{Saran}

1. Agar akurasi pada penelitian ini lebih baik, besar nilai sudut rake dapat dibuat lebih detail.

2. Salah satu cara untuk memperbaik performance propeller dengan penambahan energy saving devices.

\section{UCAPAN TERIMA KASIH}

Penulis mengucapkan terimakasih banyak kepada Jurusan S1 Teknik Perkapalan Universitas Diponegoro untuk ilmu dan pengalamannya.

\section{DAFTAR PUSTAKA}

[1] Manik, Parlindungan. (2018). Propulsi Kapal. Semarang : Teknik Perkapalan, Fakultas Teknik, Universitas Diponegoro.

[2] Wibowo, G.P., Chrismianto, D., \& A, B. A. (2017). Analisa Nilai Thrust Optimum Propeller B4-70, Ka4-70 dan Au4 59 pada Kapal Tug Boat Pelabuhan Paket-II 2x1850HP dengan Variasi Sudut Rake Menggunakan CFD, J Tek. Perkapalan, 5(1), pp 27-37.

[3] Santoso, D.H., A, B. A., \& Rindo, G. (2018). Analisa Performance Propeller Tipe B-5 Series pada Kapal Rumah Sakit Tipe Katamaran dengan Variasi Nilai Blade Area Ratio (AE/A0) dan Pitch Ratio (P/D) Menggunakan Metode Computational Fluid Dynamic (CFD), J. Tek. Perkapalan, 6(1), pp. 101-110.

[4] Budi, P. B. S., Chrismianto, D., \& Rindo, G. (2016). Analisa Nilai Thrust dan Torque Propeller Tipe B-Series pada Kapal Selam Midget 150M rengan Variasi Skew Angle dan Blade Area Ratio (Ae/Ao) Menggunakan Metode Cfd, J. Tek. Perkapalan, 13(3), pp. 109.

[5] Simbolon, H., Trimulyono, A., \& Rindo, G. (2015). Analisa Nilai Maximum Thrust Propeller B-Series dan Kaplan Series pada Kapal Tugboat Ari 400 Hp dengan Variasi Diameter, Jumlah Daun, Sudut Rake Menggunakan CFD, J. Tek. Perkapalan, 3(4), pp. 394-404.

[6] Andilolo, Y.R., Manik, P., \& Iqbal, M. (2017). Studi Kasus Kinerja Propeller Kaplan Series Akibat Pengurangan Diameter dan Penambahan End Plate dengan Metode CFD, J. Tek. Perkapalan, 5(1), pp. 205-213.

[7] Darmawan, D. B., Chrismianto, D., \& Iqbal,M. (2016). Analisa Pengaruh Sudut Kemiringan Hub Propeller Tipe B-Series pada Kapal Selam Tipe Menengah untuk Mengoptimalkan Kinerja Kapal Selam dengan Metode CFD, J. Tek. Perkapalan, 4(2), pp. 352-361.

[8] Carlton, John S. (2012). Marine Propellers and Propulsion. London : Elsevier Ltd.

[9] Bernitsas, M.M., dkk. (1981). Kt,Kq and Efficiency Curves for the Wageningen B-Series Propellers. Ann Arbor: Departement of Naval Architecture and Marine Engineering College of Engineering The University Of Michingan.

[10] Molland, Anthony F., Stephen R. Turnock, dan Dominic A. Hudson. (2011). Ship Resistance and Propulsion: Practical Estimation of Ship Propulsive Power. New York : Cambridge University Press. 